\title{
Regulatory Roles of Antimicrobial Peptides in the Nervous System: Implications for Neuronal Aging
}

\author{
Bradey A. R. Stuart ${ }^{1}$, Ariel L. Franitza ${ }^{1}$ and Lezi $E^{1,2 *}$ \\ ${ }^{1}$ Neuroscience Research Center, Medical College of Wisconsin, Milwaukee, WI, United States, ${ }^{2}$ Department of Cell Biology, \\ Neurobiology and Anatomy, Medical College of Wisconsin, Milwaukee, WI, United States
}

OPEN ACCESS

Edited by:

Xiaodi Chen,

Women \& Infants Hospital of Rhode Island, United States

Reviewed by: Alerie Guzman De La Fuente,

Queen's University Belfast, United Kingdom

David Andrew Wassarman, University of Wisconsin-Madison, United States

*Correspondence:

Lezi E

lezie@mcw.edu

Specialty section:

This article was submitted to

Cellular Neuropathology,

a section of the journal

Frontiers in Cellular Neuroscience

Received: 26 December 2021

Accepted: 31 January 2022

Published: 07 March 2022

Citation:

Stuart BAR, Franitza AL and EL

(2022) Regulatory Roles of

Antimicrobial Peptides in the Nervous

System: Implications for Neuronal

Aging.

Front. Cell. Neurosci. 16:843790.

doi: 10.3389/fncel.2022.843790
Antimicrobial peptides (AMPs) are classically known as important effector molecules in innate immunity across all multicellular organisms. However, emerging evidence begins to suggest multifunctional properties of AMPs beyond their antimicrobial activity, surprisingly including their roles in regulating neuronal function, such as sleep and memory formation. Aging, which is fundamental to neurodegeneration in both physiological and disease conditions, interestingly affects the expression pattern of many AMPs in an infection-independent manner. While it remains unclear whether these are coincidental events, or a mechanistic relationship exists, previous studies have suggested a close link between AMPs and a few key proteins involved in neurodegenerative diseases. This review discusses recent literature and advances in understanding the crosstalk between AMPs and the nervous system at both molecular and functional levels, with the aim to explore how AMPs may relate to neuronal vulnerability in aging.

Keywords: antimicrobial peptide (AMP), aging, neurodegeneration, neurodegenerative diseases, Alzheimer's disease, nervous system, neuropeptide

\section{INTRODUCTION}

Antimicrobial peptides (AMPs) are short, typically cationic peptides that are found in every kingdom of life and were originally discovered as host defense peptides. As part of the innate immune system, AMPs fight off pathogens such as bacteria, fungi, parasites, and enveloped viruses, through their insertion and subsequent disruption of the membrane structure of microbe, or having interactions with microbial intracellular/intraviral components, or a combination of both (Raheem and Straus, 2019; Benfield and Henriques, 2020). Their ability to directly act upon and kill pathogens makes them an ideal target for use as therapeutic anti-infectives, and a potential alternative to traditional antibiotics, resulting in numerous rational design studies to create synthetic AMPs (Mahlapuu et al., 2016, 2020; Cardoso et al., 2020). With over 3000 characterized AMPs to date (Antimicrobial Peptide Database, 2021, https://aps.unmc.edu/), AMPs are typically classified according to their structure and source, but other classifications include their amino acid composition or activity against different types of pathogens (Huan et al., 2020). For example, in human, some of the most prevalent and well-studied AMPs are the defensins, and the cathelicidin LL-37, which have a beta-sheet or alpha-helix motif, respectively (Wang, 2014). LL-37 is expressed ubiquitously in tissues throughout the body including epithelial cells, immune cells, and the nervous system (Dürr et al., 2006; Lee et al., 2015), while other AMPs have the greatest abundance in barrier tissues where exposure to microbes is frequent, such as the skin, airways, and intestinal epithelium (Laube et al., 2006; Kenshi and Richard, 2008; Muniz et al., 2012). For an in-depth discussion of the mechanisms 
of actions in the immune system and classification of various AMPs, which is out of the scope of current discussion, see the following reviews (Huan et al., 2020; Zhang et al., 2021).

AMPs have immense functional diversity. In addition to their antimicrobial function, a number of AMPs can act as anticancer, anti-biofilm, anti-diabetic, and wound healing agents (Mangoni et al., 2016; Di Somma et al., 2020; Tornesello et al., 2020; Soltaninejad et al., 2021). Surprisingly, recent work begins to suggest a potential alternative role of AMPs as signaling molecules to regulate cell behaviors in various tissues. In this review, we highlight and focus on recent advances in understanding the alternative roles of AMPs in the nervous system, particularly within the context of aging and neurodegenerative diseases, and summarize the open questions of this rapidly expanding field.

\section{AMPS AND NERVOUS SYSTEM}

Although classically thought of as the first line of defense between the environment and our own barrier tissues, emerging evidence suggests an intricate link between AMPs and the nervous system. For example, psychological stress dramatically downregulates the expression of cathelin-related AMP (CRAMP) in the skin of mice, increasing their susceptibility to cutaneous infections, and transforming growth factor-beta signaling from neurons non-cell autonomously regulates the AMP $c n c-2$ expression in the skin of Caenorhabditis elegans (C. elegans) (Aberg et al., 2007; Zugasti and Ewbank, 2009) (Table 1). Additionally, work by $\mathrm{E}$ et al. (2018) and Sinner et al. (2021) reveals that a skinexpressed AMP, neuropeptide-like protein 29 (NLP-29), has specific functions in inducing neurodegeneration and promoting sleep in C. elegans. Together, these data suggest the involvement of AMPs in the bidirectional interactions between the nervous system and non-neuronal tissues. In this section we explore the cellular and molecular mechanisms underlying such interactions, by specifically discussing the roles of AMPs in modulating neuroinflammation, their similarity to neuropeptides, and their functions in the central nervous system (CNS).

\subsection{AMPs and Neuroinflammation}

Inflammation of the brain and spinal cord is referred to as neuroinflammation, and much of this response is generated through the action of the CNS resident macrophages, known as microglia. Neuroinflammation can be induced in response to infection, injury, stress, and aging (DiSabato et al., 2016). Although it is important in recovery and protection of the nervous system, uncontrolled, excessive neuroinflammation can lead to cellular damage (Cherry et al., 2014; Kielian, 2014) and is implicated in a broad spectrum of neurological disorders, from traumatic to chronic neurodegenerative and ischemic brain damage.

Pattern recognition receptors (PRRs) are important mediators of inflammation that respond to exogenous infectious ligands (pathogen-associated molecular patterns, PAMPs), such as lipopolysaccharide (LPS), and endogenous molecules that are released during tissue/cellular damage (damage-associated molecular patterns, DAMPs) (Amarante-Mendes et al., 2018).
Toll-like receptors (TLRs), a family of transmembrane proteins that respond to a variety of PAMPs and DAMPs, are one of the most well studied PRRs (Hanke and Kielian, 2011; Kawasaki and Kawai, 2014). When activated, TLRs, which are expressed in both non-immune cells and immune cells including microglia, can lead to an increase in a series of inflammatory signaling molecules (Kawasaki and Kawai, 2014) as well as AMPs in human and mice (Thoma-Uszynski et al., 2001; Hertz et al., 2003; Rivas-Santiago et al., 2008).

Clinically, the levels of the AMPs LL-37 and defensins increase in the cerebrospinal fluid (CSF) in response to a bacterial meningitis challenge, and the CSF of patients with bacterial meningitis has antimicrobial activities against both Gram-positive and -negative bacteria (Maffei et al., 1999; Brandenburg et al., 2008), suggesting AMPs may directly contribute to the killing of pathogens in the nervous system. Interestingly, however, AMPs can be both anti-inflammatory and pro-inflammatory in the nervous system, depending on the context. In support of the anti-inflammatory properties of AMPs, intracerebroventricular infusion of CRAMP decreases the mortality rate in a mouse model of bacterial meningitis, likely associated with the reduction in the abundance of proinflammatory cytokines, tumor necrosis factor- $\alpha$ (TNF- $\alpha)$ and interleukin-6 (IL-6), specifically in the hippocampus (Dörr et al., 2015). Ligand binding and activation of TLR2 and TLR4 typically causes an increase in pro-inflammatory cytokines (Akira and Takeda, 2004; Kawasaki and Kawai, 2014). Cationic AMPs have been shown to bind and sequester free bacterial LPS and lipoteichoic acid (LTAs) to prevent the activation of TLR2 and TLR4 (Scott et al., 1999; Sun and Shang, 2015), possibly explaining by what mechanism AMPs may mediate an antiinflammatory response in the nervous system. Paradoxically, the CRAMP treatment in the meningitis model increases the mRNA levels of TLR2 and TLR4 (Dörr et al., 2015). On one hand, this could be anti-inflammatory, as high expression of TLRs can serve as soluble decoys to bind excess PAMP ligands (Iwami et al., 2000; Lai and Gallo, 2008), which would decrease proinflammatory signaling. Alternatively, this could also suggest a pro-inflammatory role of AMPs, as higher levels of TLR2 and TLR4 may lead to an increased sensitivity to bacterial challenge, enhancing pro-inflammatory signaling. In support of these proinflammatory properties, LL-37 may be secreted from human neuronal cells upon stress or damage, to stimulate glial cells to release pro-inflammatory cytokines and chemokines, which in turn decreases neuronal viability in vitro (Lee et al., 2015). This raises the possibility that LL-37 acts as a signaling molecule to activate glial cells within the CNS.

Although it is unknown which receptor(s) mediates LL-37induced glial activation, in other cell types LL-37 has been shown to activate a variety of $G$ protein-coupled receptors (GPCRs), receptor tyrosine kinases, ligand-gated ion channels, or TLRs (Larrick et al., 1991; Elssner et al., 2004; Brandenburg et al., 2010; Verjans et al., 2016) which may be potential targets. Previous evidence shows that LL-37 can function as chemoattractant to neutrophils and eosinophils in other tissues through its interactions with formyl peptide receptors, a class of GPCRs involved in chemotaxis (Tjabringa et al., 2006; 
TABLE 1 | Selected AMPs discussed in this review.

\begin{tabular}{|c|c|c|c|c|c|c|}
\hline $\begin{array}{l}\text { AMP and AMP- } \\
\text { like protein }\end{array}$ & Host organism & Structural motif & Charge & Tissue expressed in & Functions & Orthologues \\
\hline LL-37 & Human & Alpha helix & +6 & $\begin{array}{l}\text { Lung, colon, esophagus, skin, } \\
\text { eyes, CNS, } \\
\text { immune cells, epithelia } \\
\text { (Dürr et al., 2006; Lee et al., } \\
\text { 2015) }\end{array}$ & $\begin{array}{l}\text { Host defense, nucleic acid presentation, } \\
\text { immunomodulation, } \\
\text { chemotaxis (Kahlenberg and Kaplan, 2013) }\end{array}$ & $\begin{array}{l}\text { Rat, mouse, chicken, rabbit, } \\
\text { dog, } \\
\text { vertebrates } \\
\text { (Scheenstra et al., 2020) }\end{array}$ \\
\hline hBD-1,2,3 & Human & $\begin{array}{l}\text { Alpha helix and } \\
\text { beta sheets }\end{array}$ & $+4-11$ & $\begin{array}{l}\text { Skin, lung, trachea, } \\
\text { eyes, colon, CNS, testis, } \\
\text { immune cells (Pazgier et al., } \\
\text { 2006) }\end{array}$ & $\begin{array}{l}\text { Host defense, wound healing, chemokine, } \\
\text { angiogenesis (Ghosh et al., 2019) }\end{array}$ & $\begin{array}{l}\text { Plants, vertebrates, } \\
\text { invertebrates, insects } \\
\text { (Pazgier et al., 2006) }\end{array}$ \\
\hline PACAP & Human & Alpha helix & +11 & $\begin{array}{l}\text { Nervous system (Hirabayashi } \\
\text { et al., 2018) }\end{array}$ & $\begin{array}{l}\text { Neuropeptide, proliferation, metabolism, apoptosis, } \\
\text { differentiation, } \\
\text { immune system, potential host defense } \\
\text { (Sherwood et al., 2000; Lee et al., 2021) }\end{array}$ & $\begin{array}{l}\text { Vertebrates, invertebrates, } \\
\text { Drosophila, chicken, } \\
\text { lizard, frog, fish (Montero et al., } \\
\text { 2000) }\end{array}$ \\
\hline NLP-29 & C. elegans & $\begin{array}{l}\text { Predicted alpha } \\
\text { helix }\end{array}$ & +6 & Skin (Pujol et al., 2008) & $\begin{array}{l}\text { Host defense, wound healing, sleep, neuronal aging } \\
\text { (Pujol et al., 2008; E et al., 2018; Sinner et al., 2021) }\end{array}$ & Nematode \\
\hline CNC-2 & C. elegans & $\begin{array}{l}\text { Predicted alpha } \\
\text { helix }\end{array}$ & +3 & Skin (Zugasti and Ewbank, 2009) & $\begin{array}{l}\text { Host defense against fungal infection (Zehrbach } \\
\text { et al., 2017) }\end{array}$ & Nematode \\
\hline Metchnikowin & Drosophila & Alpha helix & +2 & Fat body, epithelia & $\begin{array}{l}\text { Host defense, mortality following TBI, potentially } \\
\text { cytotoxic, potentially } \\
\text { involved in sleep } \\
\text { (Dissel et al., 2015; Badinloo et al., 2018; Swanson } \\
\text { et al., 2020) }\end{array}$ & Insect (Buonocore et al., 2021) \\
\hline Nemuri & Drosophila & $\begin{array}{l}\text { Predicted alpha } \\
\text { helix }\end{array}$ & +14 & N.D. Accumulates in CNS & Host defense, sleep (Toda et al., 2019) & $\begin{array}{l}\text { Insect, sequence similarity } \\
\text { to fish cathelicidins (Toda et al., } \\
\text { 2019) }\end{array}$ \\
\hline Drosocin & Drosophila & $\begin{array}{l}\text { Predicted alpha } \\
\text { helix }\end{array}$ & +5 & Fat body, epithelia & $\begin{array}{l}\text { Host defense, lifespan, potentially involed in } \\
\text { sleep (Lazzaro and Clark, 2003; Dissel et al., 2015; } \\
\text { Loch et al., 2017) }\end{array}$ & Insect (Buonocore et al., 2021) \\
\hline AttacinA & Drosophila & $\begin{array}{l}\text { Predicted alpha } \\
\text { helix }\end{array}$ & +3 & Fat body, epithelia & $\begin{array}{l}\text { Host defense, lifespan (Badinloo et al., 2018; } \\
\text { Buonocore et al., 2021) }\end{array}$ & Insect (Buonocore et al., 2021) \\
\hline Cecropin A1 & Drosophila & $\begin{array}{l}\text { Predicted alpha } \\
\text { helix }\end{array}$ & +8 & Fat body, epithelia & $\begin{array}{l}\text { Host defense, lifespan, potential cytotoxicity } \\
\text { (Badinloo et al., 2018) }\end{array}$ & Insect (Buonocore et al., 2021) \\
\hline Diptericin B & Drosophila & Unknown & +7 & Head fat body & $\begin{array}{l}\text { Host defense, memory formation (Barajas-Azpeleta } \\
\text { et al., 2018) }\end{array}$ & Insect (Buonocore et al., 2021) \\
\hline GNBP-like3 & Drosophila & Unknown & +5 & Nervous system & $\begin{array}{l}\text { Host defense, memory formation (Barajas-Azpeleta } \\
\text { et al., 2018) }\end{array}$ & Insect \\
\hline NDA-1 & Hydra Vulgaris & $\begin{array}{l}\text { Predicted beta } \\
\text { sheet }\end{array}$ & N.D & Nervous system & $\begin{array}{l}\text { Neuropeptide, modulates microbiome } \\
\text { (Augustin et al., 2017) }\end{array}$ & N/A Hydra Specific \\
\hline
\end{tabular}

CNC-2, caenacin-2; CNS, central nervous system; GNBP, Gram-negative bacteria-binding protein; hBD, human beta-defensin; N.D., not determined; N/A, not available; NLP-29, neuropeptide-like protein 29; PACAP, pituitary adenylate-cyclase-activating polypeptide. 


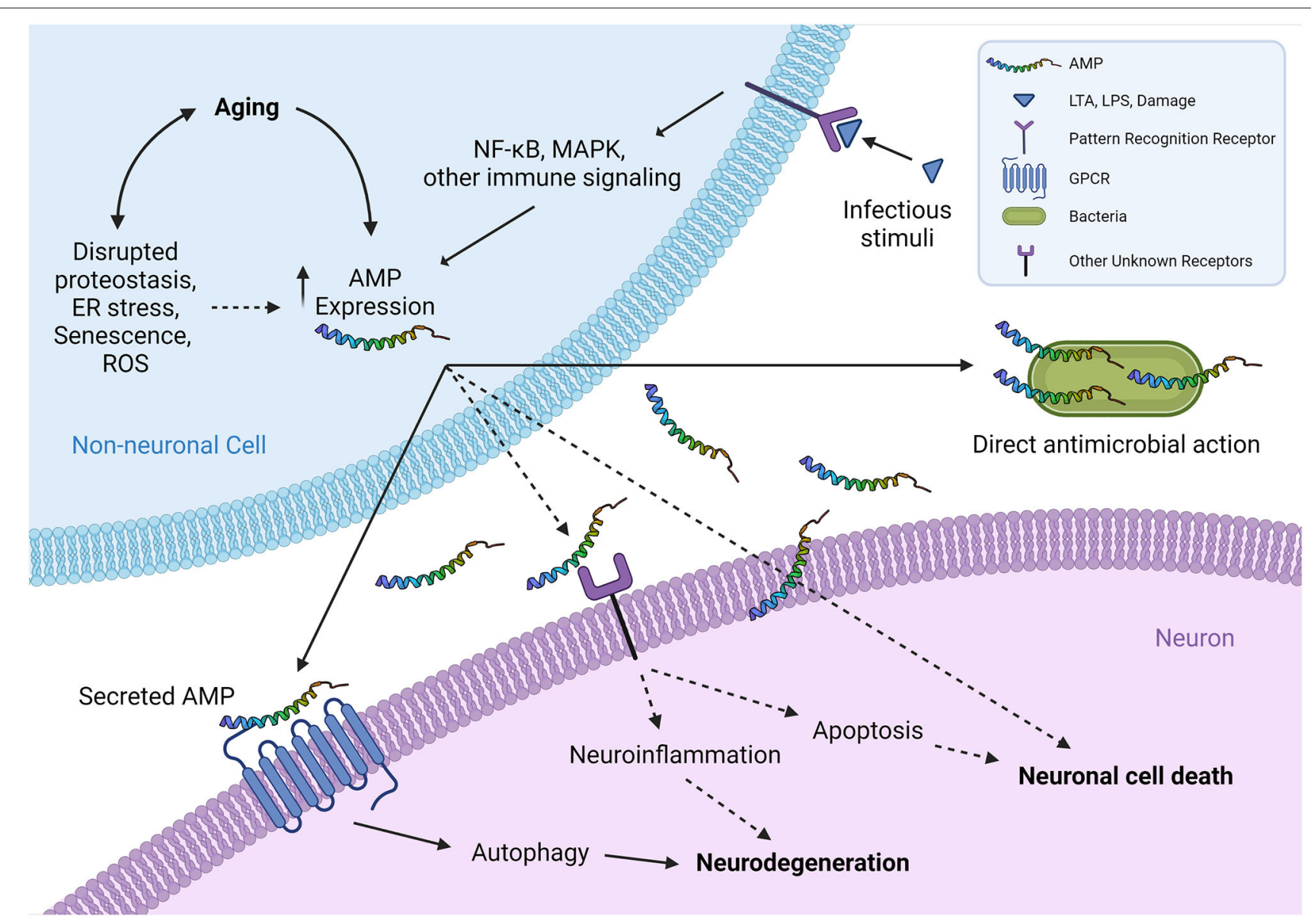

FIGURE 1 | A schematic representation of proposed interplays between non-neuronal AMPs and neurons. The expression of AMPs from non-neuronal cells (such as epidermal and intestinal epithelial cells) typically increases in infections, which can be induced by exogenous infectious stimuli or endogenous molecules that are released subsequently by damaged cells binding to pattern recognition receptors (TLRs, etc.). Aging has recently been shown as another critical factor to induce the expression of multiple AMPs at both transcriptional and translational levels, across different species, in an infection-independent manner. Overproduced AMPs are secreted from non-neuronal cells and interact with neighboring neurons by binding and activating their specific neuronal cell surface receptors, including GPCRs, and possibly other receptors as well, such as receptor tyrosine kinases or ligand-gated ion channels. This ligand-receptor binding activates the downstream signaling that eventually leads to neurodegeneration-associated function decline and/or neuronal cell death. It is tempting to speculate that certain AMPs may affect neuronal health in a receptor-independent manner, for instance by disrupting neuron membranes in a similar fashion to their mechanism of action in killing pathogens. Although the cholesterol in higher eukaryotic cell membranes generally protects the cells from attacking by endogenous AMPs (Matsuzaki, 2009), age-related changes in biophysical properties of plasma membranes (Ledesma et al., 2012) presumably can increase the susceptibility to a direct toxic interaction with the overproduced AMPs in aging. (Illustration created with Biorender.com) Solid lines denote the mechanisms supported by experimental evidence from literature; dashed lines denote potential mechanisms proposed for future investigation to clarify. AMP, antimicrobial peptide; ER, endoplasmic reticulum; GPCR, G protein-coupled receptor; LTA, lipoteichoic acid; LPS, lipopolysaccharide; MAPK, mitogen-activated protein kinase; NF- $\kappa$ B, nuclear factor-B; ROS, reactive oxygen species; TLR, Toll-like receptor.

Hemshekhar et al., 2018) which are expressed in microglia as well (Iribarren et al., 2005). It is an open question of whether expression of LL-37 also maintains its chemoattractant properties in its neuroinflammatory context. Curiously, LL-37 and other AMPs can form large crystalline complexes with endogenous or foreign dsDNA, dsRNA, ssDNA, and ssRNA, which then amplify inflammation through their interactions with TLR3, TLR9, and TLR7/8 [see (Lee et al., 2019) for a comprehensive review]. This surprising role in interacting with nucleic acids, and subsequent presentation to TLRs that mediate pro-inflammatory responses, further complicates the mechanisms of action of AMPs in neuroinflammation. The apparent diversity in whether
AMPs act as "pro" or "anti" inflammatory molecules implies that AMPs may play a critical role in maintaining the immune homeostasis within the nervous system, and also emphasizes the importance of context and experimental setup when interpreting previous literature.

\subsection{AMPs and Neuropeptides}

Neuropeptides are an evolutionarily ancient and diverse set of messengers released from the nervous system that are critical in cell-to-cell signaling. After released from neurons, the majority of neuropeptides act upon one or more GPCRs on the surface of the target cell to initiate downstream 
signaling (Russo, 2017). Neuropeptides are present both in the CNS and peripheral nervous system (PNS) and have various functions in regulating emotion, pain, digestion, and behavior (Holzer and Farzi, 2014; Kash et al., 2015; Russo, 2017). Intriguingly, neuropeptides and AMPs have remarkable structural similarities, including amphipathicity, net cationic charge, amino acid composition, and size (Brogden et al., 2005). Furthermore, multiple neuropeptides, including but not limited to human Neuropeptide Y (NPY), substance P, and $\alpha$-Melanocyte stimulating hormone, demonstrate antimicrobial activity in in vitro assays (Kowalska et al., 2002; Hansen et al., 2006; Lee and Herzog, 2009; Shireen et al., 2009). In mammals, one particularly noteworthy neuropeptide with antimicrobial properties is pituitary adenylate cyclase-activating polypeptide (PACAP) (Table 1). It has been well established that PACAP promotes differentiation of neural progenitor cells (Hirose et al., 2006), cell survival, and neurite growth (Gonzalez et al., 1997; Shioda et al., 2006; Kaneko et al., 2018). However, a recent study shows that, upon infection by Staphylococcus aureus or Candida albicans, PACAP is specifically induced in mouse brain, implying a multi-functional purpose of these neuropeptides in the intersections of immune and nervous systems (Shioda et al., 2006; Kaneko et al., 2018; Lee et al., 2021). Although it currently remains unknown whether many of these neuropeptides' in vitro antimicrobial activity translates to in vivo function, at least one neuropeptide with antimicrobial properties, NDA-1, from the model organism Hydra vulgaris contributes to the killing of Gram-positive bacteria to specifically shape a balanced microbiome on their body surface (Augustin et al., 2017) (Table 1). This shared function between AMPs and neuropeptides suggests possible evolutionary conservation of their roles and mechanisms of action in the innate immune system. Much like AMPs, neuropeptides also have immunomodulatory roles (Souza-Moreira et al., 2011; Chen et al., 2020). Considering approximately 100 neuropeptides out of the $1,000+$ small peptides predicted in the human genome have been studied (Russo, 2017), it is likely we will identify more neuropeptides with antimicrobial function in the future, potentially blurring the lines of how these peptides are defined and classified. Thus, it is tempting to speculate that AMPs may serve as the non-neuronal tissue analogues to neuropeptides to act as signaling molecules, mediators of the immune system, and neuromodulators.

\subsection{AMPs and CNS Function}

Although many AMPs are expressed where interactions with microbes is frequent, as discussed above, a growing experimental body of work suggests AMPs also exist in the CNS. Because of their lack of an adaptive immunity, the fruit fly Drosophila melanogaster has become a powerful tool for understanding the role of innate immunity components, especially AMPs in modulating the CNS (Imler and Bulet, 2005; Hanson and Lemaitre, 2020). Using this model organism, studies have discovered two AMPs functioning as necessary components of long-term memory formation. An mRNA sequencing-based screen has identified Diptericin B (DptB) as being significantly upregulated following different paradigms of behavioral training
(Barajas-Azpeleta et al., 2018) (Table 1). Subsequent knockout of DptB demonstrates that it is required for long-term memory formation, while it is produced in the fat tissues of the head, suggesting that AMPs do not need to be produced by neural tissues to regulate CNS functions. This study also identifies Gram-negative bacteria-binding protein like 3 (GNBP-like3) as a neuronally expressed AMP that is also involved in modulating memory formation. Other examples of AMPs that have been shown to regulate CNS function in Drosophila include Nemuri, which induces sleep, and Metchnikowin, which appears to promote mortality following traumatic brain injury (Toda et al., 2019; Swanson et al., 2020) (Table 1). This evidence further highlights the possibility that AMPs may serve as essential signaling molecules in the CNS to regulate behaviors and maintain organismal homeostasis.

In mammals, it remains unclear whether these regulatory roles of AMPs in CNS functions are conserved, besides particitpating in neuroinflammation. Nevertheless, the expression of the human LL-37 homologue rCRAMP (rat CRAMP) has been detected within the CNS of murine models in an infectionindependent manner (Maxwell et al., 2003; Bergman et al., 2005). Similarly in human, LL-37 has constitutive expression in the substantia nigra and sensory cortex (Lee et al., 2015), and human beta defensin-1 in the choroid plexus (Nakayama et al., 1999), despite the absence of apparent brain infections, brain injuries or other CNS disorders. What physiological role this expression in the mammalian CNS has, as of yet, remains undetermined, but we speculate that these or other AMPs are multifunctional and not limited to their microbicidal action. Behaviorally, in mice, psychological stress can reduce the expression of beta defensins in the skin, and depression can reduce alpha defensin expression in the intestine (Aberg et al., 2007; Suzuki et al., 2021). A postmortem study shows that human patients who died by suicide have decreased LL-37 expression in both dorsolateral prefrontal cortex and anterior cingulate cortex, which are critical for mood regulation (Bae et al., 2006), when compared to those who died by other causes (Postolache et al., 2020). Such evidence indicates an important correlation between AMPs and CNS functions in mammals, while it remains an area of investigation of whether they are parallel events or if there is a causal relationship. We posit that, considering other model organisms have AMPs whose actions in the nervous system originate from non-neuronal tissues (Barajas-Azpeleta et al., 2018; E et al., 2018), similar regulatory mechanisms may be conserved in mammals as well. Further work is necessary to uncover whether AMPs in human function in a physiological context to modulate CNS functions.

\section{IMPLICATION OF AMPS IN NEURODEGENERATIVE DISEASES}

Neurodegeneration, the process of progressively losing the structure or function of neurons, is the key pathophysiological feature of neurodegenerative diseases such as Alzheimer's disease (AD), Huntington's disease, amyotrophic lateral sclerosis, and Parkinson's disease (PD). In each of these diseases, it is typical 
to see accumulation of proteins, such as amyloid beta $(\mathrm{A} \beta)$ or tau in $\mathrm{AD}$, or alpha-synuclein in $\mathrm{PD}$, in an altered conformation.

Although early hypotheses attempting to explain AD etiology implicate $\mathrm{A} \beta$ as the causative agent of the disease (Hardy and Higgins, 1992), multiple other hypotheses since propose other pathways, generating much debate ( $\mathrm{Du}$ et al., 2018). More recently, a hypothesis known as the Antimicrobial Protection Hypothesis, which is extensively reviewed elsewhere (Moir et al., 2018), has garnered attention. Briefly, this hypothesis asserts that the expression and aggregation of $\mathrm{A} \beta$ is a response to pathogens, and $\mathrm{A} \beta$ oligomerization is protective against microbes, acting as an AMP. This hypothesis is based on the evidence that synthetic $\mathrm{A} \beta$ has antimicrobial properties against common pathogens in vitro, and that brain homogenates from $\mathrm{AD}$ patients have significantly higher antimicrobial activity than that from agematched non-AD controls in an $\mathrm{A} \beta$ level-dependent manner (Soscia et al., 2010). Additionally, overexpression of $\mathrm{A} \beta$ in $C$. elegans protects them from Candida albicans infection, and overproduced $\mathrm{A} \beta$ in the transgenic $5 \mathrm{xFAD}$ mouse model promotes the animal survival against Salmonella Typhimurium infection, with the evidence showing colocalization of $\mathrm{A} \beta$ deposition and the invading bacteria (Kumar et al., 2016). Early cell culture studies also show that $\mathrm{A} \beta$ has the potential to bind and cause aggregates of viral particles, specifically influenza and herpes simplex virus-1 (HSV-1) (White et al., 2014; Bourgade et al., 2015, 2016). Also in 5xFAD mice, infection with HSV1 promotes $\mathrm{A} \beta$ aggregation, and these aggregates appear to capture HSV-1 in ex vivo mouse brain tissue slices, as well as in human stem cell-derived neural cell culture (Eimer et al., 2018). However, recently repeated experiments with the same $\mathrm{AD}$ mouse model contradict these results. Bocharova et al. hypothesize that $\mathrm{A} \beta$ does not entrap viral particles, or protect against viral infection, and that such inconsistent observations may be explained by sex-specific expression of $\mathrm{A} \beta$ in $5 \mathrm{xFAD}$ mice or non-physiologically relevant levels of HSV-1 dosing used in the experiments (Bocharova et al., 2021). As such, the question of whether $\mathrm{A} \beta$ is protective, either in physiological or pathological contexts, remains vague. Elucidating the role of the antimicrobial properties of $\mathrm{A} \beta$ in human may lead to a more complete understanding of the factors causing $\mathrm{AD}$ and progression of $\mathrm{AD}$ and aid in the development of further therapeutic strategies.

Considering the aforementioned immunomodulatory roles of AMPs, both in the CNS and in other tissues, if $\mathrm{A} \beta$ was also a component of the innate immune system, one would expect $\mathrm{A} \beta$ to mediate inflammation in physiological conditions. Indeed, in vitro experiments show that microglia exposed to non-aggregated $\mathrm{A} \beta$ at low concentrations become reactive, and in turn express the AMP LL-37 as part of a pro-inflammatory response (Maezawa et al., 2011; Xu et al., 2018). Additionally, similar to human LL-37 being a chemoattractant to immune cells utilizing FPRL1 as a receptor (Yang et al., 2000), $\mathrm{A} \beta$ is a chemoattractant to mouse microglia by acting at the murine homologue of this GPCR (Tiffany et al., 2001). In human, A $\beta$ 's action upon the FPRL1 receptor causes internalization of $\mathrm{A} \beta$ into macrophages (Cui et al., 2002) and promotes inflammation (Schröder et al., 2020). Such interactions may provide context for the elusive role of the amyloid protein under physiological conditions.
Much like the other AMPs discussed, $\mathrm{A} \beta$ can cause both pro or anti-inflammatory signaling depending on the context. On the anti-inflammatory side, in vitro studies demonstrate a direct interaction of LL-37 and $\mathrm{A} \beta$, and that these interactions are protective, as LL-37 binding to $\mathrm{A} \beta$ decreases microglialmediated toxicity against neuronal cells (De Lorenzi et al., 2017). Altogether, the current data suggests that $\mathrm{A} \beta$ may be an integral component of our innate immune system, and that there may be a balance between its interactions with other AMPs during the chronic neuroinflammation typical of $\mathrm{AD}$ and thus the progression of $\mathrm{AD}$.

In other neurodegenerative diseases, the characteristic proteins also demonstrate antimicrobial action. In relation to PD, alpha-synuclein has in vitro antimicrobial activities against Escherichia coli, Staphylococcus aureus, and fungi (Park et al., 2016). In addition, the expression of alpha-synuclein in mice is also protective against RNA viruses from developing brain infections (Beatman et al., 2016). In a Drosophila model of the neurodegenerative disease ataxia-telangiectasia, ataxiatelangiectasia mutated (ATM) kinase results in increased AMP gene expression in glial cells, specifically through the NF- $\kappa \mathrm{B}$ pathway (Petersen et al., 2012, 2013). Also, Drosophila carrying the mutant form of huntingtin, had impaired expression of a few AMPs, including DptB, Attacin, and cecropin A (Table 1), following bacterial infection (Lin et al., 2019), further suggesting a delicate interrelationship between the innate immune system and some of the key proteins in neurodegenerative diseases. The correlative and common elements between AMPs and neurodegenerative diseases warrants further investigation into whether AMPs are the drivers of the diseases, or misregulated as a consequence of the progression of diseases.

\section{AMPS AND AGING}

\subsection{AMP Expression in Development and Aging}

It has been the general consensus that AMPs are expressed at a relatively low, but constitutive level, especially in tissues that interact with the environment where microbial interactions are frequent. In the presence of infection, PAMPs on microbial surfaces typically activate specific receptors, such as TLRs, that lead to activation of transcription factors that increase the abundance of AMPs (Krisanaprakornkit et al., 2000; RivasSantiago et al., 2008; Gombart, 2009) (Figure 1). However, recent evidence has begun to implicate age as a factor in regulating the expression of AMPs as well. There appear to be two major increases in AMP expression that occur over the course of an organism's life. First, at the beginning of life, AMP expression seems to increase in the developing embryo or fetus, as evidenced in Hydra, mouse, chicken, and human (Gallo et al., 1997; Meade et al., 2009; Fraune et al., 2010; Gschwandtner et al., 2014). It is thought that the overexpression of AMPs "prepares" an embryo for its first encounter with microbes upon birth. However, considering the sterile environment of the chicken egg, the conserved nature of this expression, and the aforementioned alternative 
roles of AMPs in signaling, there may be a potential non-antimicrobial biological role of these peptides during embryogenesis. Consistent with this hypothesis, human fetal keratinocytes that are cultured in the presence of antibiotics still show strong AMP expression compared to that of neonatal or adult keratinocytes, suggesting an innate, young agedependent expression mechanism (Gschwandtner et al., 2014). This developmental increase is followed by a marked decrease to a low or basal level of expression.

As organisms age, AMP expression again deviates from its baseline. Expression patterns of individual AMPs may differ, but in general, AMPs tend to gradually increase over the course of aging. One proposed mechanism of this apparent increase of AMP expression in aging populations is partially attributed to a compromised barrier between host and microbe, causing increased inflammation due to increased interactions with microbe-secreted signaling molecules. In support of this, many AMPs become dysregulated in aged mice, and these changes are associated with microbiome changes in the small intestine (Tremblay et al., 2017). In Drosophila, several studies show that aging specifically causes an increase in numerous AMPs (Kounatidis et al., 2017; Badinloo et al., 2018; Hanson and Lemaitre, 2020; Swanson et al., 2020; Wang et al., 2020). Surprisingly, flies grown in germ-free conditions still have agedependent activation of AMP expression. Similarly, aging also causes a dramatic increase in AMP expression in other model organisms despite the absence of infection. Recently, we have found that the expression of the skin-expressed AMP NLP29 gradually but significantly enhances over the course of aging in C. elegans, even with the treatment of antifungals and antibiotic compounds, suggesting the increase is specifically age dependent (E et al., 2018). Paradoxically, overexpression of certain AMPs (Attacin, Metchnikowin, cecropin A1, and Defensin) in Drosophila can impart cytotoxicity of muscle and fat cells, cognitive decline, and decreased lifespan (Kounatidis et al., 2017; Badinloo et al., 2018), while overexpression of other AMPs, such as Drosocin, extends Drosophila lifespan by specifically protecting the intestinal epithelium (Loch et al., 2017) (Table 1). These data suggest that individual AMPs may have context-specific and multifaceted physiological roles in aging.

To date, relatively few research studies have focused on elucidating the expression pattern of AMPs over the adult lifespan in human. It has been reported that the mRNA levels of human beta defensin 2 is elevated in peripheral blood mononuclear cells in aged populations (Castañeda-Delgado et al., 2013), while this observation may not be accurately reflected at the serum level (Castañeda-Delgado et al., 2017) (Table 1), as it is unclear whether any aging-associated defects complicate the peptide secretion process. However, it is noteworthy that, $\mathrm{A} \beta$, which has recently been demonstrated as an AMP, gradually and significantly increases its level in multiple brain regions of human subjects over a healthy adult lifespan (Rodrigue et al., 2012). While these data suggest that the age-dependent expression pattern of AMPs observed in other organisms appear to be conserved in human to a certain extent, further research will be required to provide more comprehensive information on how AMPs are involved in human physiological aging at the functional level.

\subsection{Contribution of AMP in Neuronal Aging}

While we still face numerous challenges in dissecting the etiology and pathogenesis of neurodegenerative diseases, there is also a fundamental gap in our understanding on how functional aging of the nervous system is switched on. Emerging evidence indicates that the degeneration of neurons can be regulated by surrounding cells (microglia and astrocytes, etc.) at the cellular and molecular levels (Glass et al., 2010). From a broader perspective, a significant amount of evidence suggests that some age-related neurodegenerative diseases, such as PD, are not only CNS disorders but also have systemic pathology and manifestations (Fasano et al., 2015), implying a close link between the non-neuronal periphery and the nervous system during aging. Several studies have highlighted the key roles of AMPs in mediating the upstream signals from non-neuronal tissues/cells to initiate neuronal aging. In Drosophila, reflected by a dramatic age-dependent increase of multiple AMPs in the brain, a conserved Relish/NF- $\kappa \mathrm{B}$ immune signaling pathway appears to be dysregulated in glial cells during functional aging, and overactivation of the pathway can result in reduced lifespan (Kounatidis et al., 2017). This dysregulation also seems largely responsible for aging-associated neuropathology, as glialspecific overexpression of individual AMP genes known to be regulated by the NF- $\kappa \mathrm{B}$ pathway is sufficient to cause the neurodegeneration phenotypes seen in physiological aging (Cao et al., 2013; Kounatidis et al., 2017). More strikingly, our previous studies have discovered an unexpected function of the skin-exclusive AMP, NLP-29, in causatively triggering the aging-associated degeneration of sensory neurons in C. elegans, without affecting the lifespan (E et al., 2018) (Table 1). This process requires a neuronal receptor (neuropeptide receptor 12, NPR-12) specific to NLP-29, enabling the transmission of neurodegeneration-initiating signals from the non-neuronal tissues to neurons, via a ligand-receptor binding mechanism (Figure 1). While we find that autophagic machinery is activated downstream of the neuropeptide receptor NPR-12 to mediate neurodegeneration [See (Wauson et al., 2014) for a review of GPCRs in the regulation of autophagy] the role of autophagy in neurodegeneration has been a controversial topic (Wong and Cuervo, 2010) and remains to be comprehensively elucidated in both physiological aging and disease conditions.

Although NLP-29 expression appears to be regulated by a conserved mitogen-activated protein kinase (MAPK) immune signaling pathway in response to pathogenic infections (Pujol et al., 2008), it is unclear whether this pathway also contributes to the age-dependent increase of this "neurodegeneration-causing AMP” in wild-type C. elegans (E et al., 2018). One possible source of internal signals that regulate such AMP increases that have regulatory effects on the nervous system, are the hallmarks of aging. These include but are not limited to increased reactive oxygen species, endoplasmic reticulum stress triggered by misfolded protein accumulation, and cellular senescence (López-Otí?n et al., 2013; Childs et al., 2015), which may also induce additional tissue/organ-specific changes on top of 
the burden generated by aging itself. While it remains to be further investigated whether AMPs contribute to agingassociated neurodegeneration in mammals, our current data suggest that this mechanism may be evolutionarily conserved, as ectopic expression of the C. elegans NPR-12/GPCR, in the presence of the ligand NLP-29, stimulates rat cortical neurons to degenerate in vitro (E et al., 2018). Considering the conservation of aging-associated expression patterns of AMPs in other organisms, we stress the necessity and importance of future research to explore the crosstalk between AMPs and nervous system in mammalian systems within the context of physiological aging, which likely will add significantly to our understanding of the biological root of neuronal aging.

\section{PERSPECTIVES}

In the many years since the discovery of AMPs, researchers have continued to unveil novel functions of these pleotropic molecules. The involvement of AMPs in physiological and pathological aging appears to be a common theme across multicellular organisms, and of recent note, AMPs have garnered more interest in their roles as regulators of the nervous system. Previous studies have highlighted a possibility that AMPs may serve as important signaling molecules that originate from non-neuronal tissues to mediate the progression of aging, neurodegeneration (Figure 1), and subsequent changes in organismal behaviors, while most of these studies investigate such interactions in non-mammalian model systems. With age-dependent increase of various AMPs being a conserved phenomenon across different species in different tissues, as well as the recent evidence implying antimicrobial-related function

\section{REFERENCES}

Aberg, K. M., Radek, K. A., Choi, E.-H., Kim, D.-K., Demerjian, M., Hupe, M., et al. (2007). Psychological stress downregulates epidermal antimicrobial peptide expression and increases severity of cutaneous infections in mice. J. Clin. Investigat. 117, 3339-3349. doi: 10.1172/JCI3 1726

Akira, S., and Takeda, K. (2004). Toll-like receptor signalling. Nat. Rev. Immunol. 4, 499-511. doi: 10.1038/nri1391

Amarante-Mendes, G. P., Adjemian, S., Branco, L. M., Zanetti, L. C., Weinlich, R., and Bortoluci, K. R. (2018). Pattern recognition receptors and the host cell death molecular machinery. Front. in Immunol. 9, 2379. doi: 10.3389/fimmu.2018.02379

Augustin, R., Schröder, K., Murillo Rincón, A. P., Fraune, S., Anton-Erxleben, F., Herbst, E.-M., et al. (2017). A secreted antibacterial neuropeptide shapes the microbiome of hydra. Nat. Commun. 8, 698. doi: 10.1038/s41467-017-00625-1

Badinloo, M., Nguyen, E., Suh, W., Alzahrani, F., Castellanos, J., Klichko, V. I., et al. (2018). Overexpression of antimicrobial peptides contributes to aging through cytotoxic effects in Drosophila tissues. Arch. Insect Biochem. Physiol. 98, e21464. doi: 10.1002/arch.21464

Bae, J. N., MacFall, J. R., Krishnan, K. R. R., Payne, M. E., Steffens, D. C., and Taylor, W. D. (2006). Dorsolateral prefrontal cortex and anterior cingulate cortex white matter alterations in late-life depression. Biol. Psychiatry 60, 1356-1363. doi: 10.1016/j.biopsych.2006.03.052

Barajas-Azpeleta, R., Wu, J., Gill, J., Welte, R., Seidel, C., McKinney, S., et al. (2018). Antimicrobial peptides modulate long-term memory. PLoS Genet. 14, e1007440. doi: 10.1371/journal.pgen.1007440 of the characteristic proteins associated with neurodegenerative diseases, there remain essential and critical questions to be answered from a translational perspective. For instance, what are the evolutionary reasons for AMPs to increase their expression levels in functional aging? What molecular mechanisms regulate AMP expression in the absence of pathogenic infections? Are there any common features among the AMPs that can potentially affect neuronal health in aging, such as requiring specific groups of neuronal surface receptors to mediate the effects? Revealing the mechanisms underlying these intricate phenomena will likely lead to future identification of key biomarkers for preventative health screenings and diagnostics for age-related neurological disorders, and aid in the development of novel therapeutic targets.

\section{AUTHOR CONTRIBUTIONS}

BS and LE performed the literature search and drafted the manuscript. AF and LE edited the manuscript. All authors contributed to the article and approved the submitted version.

\section{FUNDING}

This work was supported by the Imagine More Award, Research Affairs Committee, as well as the Department of Cell Biology, Neurobiology, and Anatomy at the Medical College of Wisconsin, and 5520482 Advancing a Healthier Wisconsin (AHW) Endowment project titled Developing Innovative Translational Research Programs in Clinically Relevant Neurological Disorders.

Beatman, E. L., Massey, A., Shives, K. D., Burrack, K. S., Chamanian, M., Morrison, T. E., et al. (2016). Alpha-synuclein expression restricts RNA viral infections in the brain. J. Virol. 90, 2767-2782. doi: 10.1128/JVI. 02949-15

Benfield, A. H., and Henriques, S. T. (2020). Mode-of-action of antimicrobial peptides: membrane disruption vs. intracellular mechanisms. Front. Med. Technol. 2, 20. doi: 10.3389/fmedt.2020.610997

Bergman, P., Termén, S., Johansson, L., Nyström, L., Arenas, E., Jonsson, A.-B., et al. (2005). The antimicrobial peptide rCRAMP is present in the central nervous system of the rat. J. Neurochem. 93, 1132-1140. doi: 10.1111/j.1471-4159.2005.03081.x

Bocharova, O., Pandit, N. P., Molesworth, K., Fisher, A., Mychko, O., Makarava, N., et al. (2021). Alzheimer's disease-associated-amyloid does not protect against herpes simplex virus 1 infection in the mouse brain. J. Biol. Chem. 297, 100845. doi: 10.1016/j.jbc.2021.100845

Bourgade, K., Garneau, H., Giroux, G., Le Page, A. Y., Bocti, C., Dupuis, G., et al. (2015). $\beta$-Amyloid peptides display protective activity against the human Alzheimer's disease-associated herpes simplex virus-1. Biogerontology 16, 8598. doi: 10.1007/s10522-014-9538-8

Bourgade, K., Le Page, A., Bocti, C., Witkowski, J. M., Dupuis, G., Frost, E. H., et al. (2016). Protective effect of amyloid- $\beta$ peptides against herpes simplex virus-1 infection in a neuronal cell culture model. J. Alzheimer's Dis. JAD 50, 1227-1241. doi: 10.3233/JAD-150652

Brandenburg, L.-O., Jansen, S., Wruck, C. J., Lucius, R., and Pufe, T. (2010). Antimicrobial peptide rcramp induced glial cell activation through p2y receptor signalling pathways. Mol. Immunol. 47, 1905-1913. doi: 10.1016/j.molimm.2010.03.012 
Brandenburg, L.-O., Varoga, D., Nicolaeva, N., Leib, S. L., Wilms, H., Podschun, R., et al. (2008). Role of glial cells in the functional expression of LL-37/rat cathelin-related antimicrobial peptide in meningitis. J. Neuropathol. Exp. Neurol. 67, 1041-1054. doi: 10.1097/NEN.0b013e31818b4801

Brogden, K. A., Guthmiller, J. M., Salzet, M., and Zasloff, M. (2005). The nervous system and innate immunity: the neuropeptide connection. Nat. Immunol. 6, 558-564. doi: 10.1038/ni1209

Buonocore, F., Fausto, A. M., Della Pelle, G., Roncevic, T., Gerdol, M., and Picchietti, S. (2021). Attacins: a promising class of insect antimicrobial peptides. Antibiotics 10, 212. doi: 10.3390/antibiotics10020212

Cao, Y., Chtarbanova, S., Petersen, A. J., and Ganetzky, B. (2013). Dnr1 mutations cause neurodegeneration in Drosophila by activating the innate immune response in the brain. Proc. Natl. Acad. Sci. U.S.A. 110, E1752-E1760. doi: 10.1073/pnas.1306220110

Cardoso, M. H., Orozco, R. Q., Rezende, S. B., Rodrigues, G., Oshiro, K. G. N., Cândido, E. S., et al. (2020). Computer-aided design of antimicrobial peptides: are we generating effective drug candidates? Front. Microbiol. 10, 03097. doi: $10.3389 /$ fmicb. 2019.03097

Castan̄eda-Delgado, J. E., Frausto-Lujan, I., González-Curiel, I., MontoyaRosales, A., Serrano, C. J., Torres-Juarez, F., et al. (2017). Differences in cytokine production during aging and its relationship with antimicrobial peptides production. Immunol. Investigat. 46, 48-58. doi: $10.1080 / 08820139.2016 .1212873$

Castan̄eda-Delgado, J. E., Miranda-Castro, N. Y., González-Amaro, R., GonzálezCuriel, I., Montoya-Rosales, A., Rivas-Calderon, B., et al. (2013). Production of antimicrobial peptides is preserved in aging. Clin. Immunol. 148, 198-205. doi: 10.1016/j.clim.2013.05.015

Chen, W.-C., Liu, Y.-B., Liu, W.-F., Zhou, Y.-Y., He, H.-F., and Lin, S. (2020). Neuropeptide y is an immunomodulatory factor: direct and indirect. Front. Immunol. 11, 580378. doi: 10.3389/fimmu.2020.580378

Cherry, J. D., Olschowka, J. A., and O'Banion, M. K. (2014). Neuroinflammation and M2 microglia: the good, the bad, and the inflamed. J. Neuroinflammation 11, 98. doi: 10.1186/1742-2094-11-98

Childs, B. G., Durik, M., Baker, D. J., and van Deursen, J. M. (2015). Cellular senescence in aging and age-related disease: from mechanisms to therapy. Nat. Med. 21, 1424-1435. doi: 10.1038/nm.4000

Cui, Y., Le, Y., Yazawa, H., Gong, W., and Wang, J. M. (2002). Potential role of the formyl peptide receptor-like 1 (FPRL1) in inflammatory aspects of Alzheimer's disease. J. Leukocyte Biol. 72, 628-635. doi: 10.1189/jlb.72.4.628

De Lorenzi, E., Chiari, M., Colombo, R., Cretich, M., Sola, L., Vanna, R., et al. (2017). Evidence that the human innate immune peptide LL-37 may be a binding partner of amyloid- $\beta$ and inhibitor of fibril assembly. J. Alzheimer's Dis. 59, 1213-1226. doi: 10.3233/JAD-170223

Di Somma, A., Moretta, A., Canè, C., Cirillo, A., and Duilio, A. (2020). Antimicrobial and antibiofilm peptides. Biomolecules 10, 652. doi: 10.3390/biom10040652

DiSabato, D., Quan, N., and Godbout, J. P. (2016). Neuroinflammation: the devil is in the details. J. Neurochem. 139, 136-153. doi: 10.1111/jnc.13607

Dissel, S., Seugnet, L., Thimgan, M. S., Silverman, N., Angadi, V., Thacher, P. V., et al. (2015). Differential activation of immune factors in neurons and glia contribute to individual differences in resilience/vulnerability to sleep disruption. Brain Behav. Immun. 47, 75-85. doi: 10.1016/j.bbi.2014.09.019

Dörr, A., Kress, E., Podschun, R., Pufe, T., Tauber, S. C., and Brandenburg, L.-O. (2015). Intrathecal application of the antimicrobial peptide CRAMP reduced mortality and neuroinflammation in an experimental model of pneumococcal meningitis. J. Infect. 71, 188-199. doi: 10.1016/j.jinf.2015.04.006

Du, X., Wang, X., and Geng, M. (2018). Alzheimer's disease hypothesis and related therapies. Transl. Neurodegen. 7, 2. doi: 10.1186/s40035-018-0107-y

Dürr, U. H. N., Sudheendra, U. S., and Ramamoorthy, A. (2006). LL-37, the only human member of the cathelicidin family of antimicrobial peptides. Biochimica et Biophysica Acta (BBA) - Biomembranes 1758, 1408-1425. doi: 10.1016/j.bbamem.2006.03.030

E, L., Zhou, T., Koh, S., Chuang, M., Sharma, R., Pujol, N. et al. (2018). An Antimicrobial Peptide and Its Neuronal Receptor Regulate Dendrite Degeneration in Aging and Infection. Neuron 97, 125-138.e5. doi: 10.1016/j.neuron.2017.12.001

Eimer, W. A., Vijaya Kumar, D. K., Navalpur Shanmugam, N. K., Rodriguez, A. S., Mitchell, T., Washicosky, K. J., et al. (2018). Alzheimer's disease-associated $\beta$-amyloid is rapidly seeded by herpesviridae to protect against brain infection. Neuron 99, 56-63.e3. doi: 10.1016/j.neuron.2018.06.030
Elssner, A., Duncan, M., Gavrilin, M., and Wewers, M. D. (2004). A novel $\mathrm{p} 2 \mathrm{x} 7$ receptor activator, the human cathelicidin-derived peptide 1137, induces il-1 $\beta$ processing and release. J. Immunol. 172, 4987-4994. doi: 10.4049/jimmunol.172.8.4987

Fasano, A., Visanji, N. P., Liu, L. W. C., Lang, A. E., and Pfeiffer, R. F. (2015). Gastrointestinal dysfunction in Parkinson's disease. Lancet Neurol. 14, 625639. doi: 10.1016/S1474-4422(15)00007-1

Fraune, S., Augustin, R., Anton-Erxleben, F., Wittlieb, J., Gelhaus, C., Klimovich, V. B., et al. (2010). In an early branching metazoan, bacterial colonization of the embryo is controlled by maternal antimicrobial peptides. Proc. Natl. Acad. Sci. U.S.A. 107, 18067-18072. doi: 10.1073/pnas.1008573107

Gallo, R. L., Kim, K. J., Bernfield, M., Kozak, C. A., Zanetti, M., Merluzzi, L., et al. (1997). Identification of CRAMP, a cathelin-related antimicrobial peptide expressed in the embryonic and adult mouse. J. Biol. Chem. 272, 13088-13093. doi: $10.1074 / j b c .272 .20 .13088$

Ghosh, S. K., McCormick, T. S., and Weinberg, A. (2019). Human beta defensins and cancer: contradictions and common ground. Front. Oncol. 9, 341. doi: $10.3389 /$ fonc. 2019.00341

Glass, C. K., Saijo, K., Winner, B., Marchetto, M. C., and Gage, F. H. (2010). Mechanisms underlying inflammation in neurodegeneration. Cell 140, 918934. doi: 10.1016/j.cell.2010.02.016

Gombart, A. F. (2009). The vitamin D-antimicrobial peptide pathway and its role in protection against infection. Future Microbiol. 4, 1151-1165. doi: $10.2217 / \mathrm{fmb} .09 .87$

Gonzalez, B. J., Basille, M., Vaudry, D., Fournier, A., and Vaudry, H. (1997). Pituitary adenylate cyclase-activating polypeptide promotes cell survival and neurite outgrowth in rat cerebellar neuroblasts. Neuroscience 78, 419-430. doi: 10.1016/S0306-4522(96)00617-3

Gschwandtner, M., Zhong, S., Tschachler, A., Mlitz, V., Karner, S., Elbe-Bürger, A., et al. (2014). Fetal human keratinocytes produce large amounts of antimicrobial peptides: involvement of histone-methylation processes. $J$. Investigat. Dermatol. 134, 2192-2201. doi: 10.1038/jid.2014.165

Hanke, M. L., and Kielian, T. (2011). Toll-like receptors in health and disease in the brain: mechanisms and therapeutic potential. Clin. Sci. (London, England: 1979) 121, 367-387. doi: 10.1042/CS20110164

Hansen, C. J., Burnell, K. K., and Brogden, K. A. (2006). Antimicrobial activity of substance $\mathrm{P}$ and neuropeptide $\mathrm{Y}$ against laboratory strains of bacteria and oral microorganisms. J. Neuroimmunol. 177, 215-218. doi: 10.1016/j.jneuroim.2006.05.011

Hanson, M. A., and Lemaitre, B. (2020). New insights on Drosophila antimicrobial peptide function in host defense and beyond. Curr. Opin. Immunol. 62, 22-30. doi: 10.1016/j.coi.2019.11.008

Hardy, J. A., and Higgins, G. A. (1992). Alzheimer's disease: the amyloid cascade hypothesis. Science 256, 184-185. doi: 10.1126/science.1566067

Hemshekhar, M., Choi, K.-Y. G., and Mookherjee, N. (2018). Host defense peptide LL-37-mediated chemoattractant properties, but not anti-inflammatory cytokine IL-1RA production, is selectively controlled by Cdc 42 Rho GTPase via $\mathrm{G}$ protein-coupled receptors and JNK mitogen-activated protein kinase. Front. Immunol. 9, 1871. doi: 10.3389/fimmu.2018.01871

Hertz, C. J., Wu, Q., Porter, E. M., Zhang, Y. J., Weismüller, K.-H., Godowski, P. J., et al. (2003). Activation of toll-like receptor 2 on human tracheobronchial epithelial cells induces the antimicrobial peptide human defensin-2. J. Immunol. 171, 6820-6826. doi: 10.4049/jimmunol.171.12.6820

Hirabayashi, T., Nakamachi, T., and Shioda, S. (2018). Discovery of PACAP and its receptors in the brain. J. Headache Pain 19, 28. doi: 10.1186/s10194-018-0855-1

Hirose, M., Hashimoto, H., Iga, J., Shintani, N., Nakanishi, M., Arakawa, N., et al. (2006). Inhibition of self-renewal and induction of neural differentiation by PACAP in neural progenitor cells. Ann. New York Acad. Sci. 1070, 342-347. doi: 10.1196/annals.1317.042

Holzer, P., and Farzi, A. (2014). Neuropeptides and the microbiota-gut-brain axis. Adv. Exp. Med. Biol. 817, 195-219. doi: 10.1007/978-1-4939-0897-49

Huan, Y., Kong, Q., Mou, H., and Yi, H. (2020). Antimicrobial peptides: classification, design, application and research progress in multiple fields. Front. Microbiol. 11:582779. doi: 10.3389/fmicb.2020.582779

Imler, J.-L. and Bulet, P. (2005). Antimicrobial peptides in drosophila: structures,activities and gene regulation. Mech. Epithelial Defense 86, 1-21. doi: $10.1159 / 000086648$

Iribarren, P., Zhou, Y., Hu, J., Le, Y., and Wang, J. M. (2005). Role of formyl peptide receptor-like 1 (FPRL1/FPR2) in mononuclear phagocyte responses in alzheimer disease. Immunol. Res. 31, 165-176. doi: 10.1385/IR:31:3:165 
Iwami, K.-I., Matsuguchi, T., Masuda, A., Kikuchi, T., Musikacharoen, T., and Yoshikai, Y. (2000). Cutting edge: naturally occurring soluble form of mouse toll-like receptor 4 inhibits lipopolysaccharide signaling. J. Immunol. 165, 6682-6686. doi: 10.4049/jimmunol.165.12.6682

Kahlenberg, J. M., and Kaplan, M. J. (2013). Little peptide, big effects: the role of LL-37 in inflammation and autoimmune disease. J. Immunol. (Baltimore, $M d$. : 1950) 191, 4895-4901. doi: 10.4049/jimmunol.1302005

Kaneko, Y., Tuazon, J. P., Ji, X., and Borlongan, C. V. (2018). Pituitary adenylate cyclase activating polypeptide elicits neuroprotection against acute ischemic neuronal cell death associated with NMDA receptors. Cell. Physiol. Biochem. 51, 1982-1995. doi: 10.1159/000495722

Kash, T. L., Pleil, K. E., Marcinkiewcz, C. A., Lowery-Gionta, E. G., Crowley, N., Mazzone, C., et al. (2015). Neuropeptide regulation of signaling and behavior in the BNST. Mol. Cells 38, 1-13. doi: 10.14348/molcells.2015.2261

Kawasaki, T., and Kawai, T. (2014). Toll-like receptor signaling pathways. Front. Immunol. 5, 461. doi: 10.3389/fimmu.2014.00461

Kenshi, Y., and Richard, L. G. (2008). Antimicrobial peptides in human skin disease. Eur. J. Dermatol. EJD 18, 11-21. doi: 10.1684/ejd.2008.0304

Kielian, T. (2014). Neuroinflammation: good, bad, or indifferent? J. Neurochem. 130, 1-3. doi: 10.1111/jnc. 12755

Kounatidis, I., Chtarbanova, S., Cao, Y., Hayne, M., Jayanth, D., Ganetzky, B., et al. (2017). NF-B immunity in the brain determines fly lifespan in healthy aging and age-related neurodegeneration. Cell Rep. 19, 836-848. doi: 10.1016/j.celrep.2017.04.007

Kowalska, K., Carr, D. B., and Lipkowski, A. W. (2002). Direct antimicrobial properties of substance P. Life Sci. 71, 747-750. doi: 10.1016/S0024-3205(02)01740-X

Krisanaprakornkit, S., Kimball, J. R., Weinberg, A., Darveau, R. P., Bainbridge, B. W., and Dale, B. A. (2000). Inducible expression of human beta-defensin 2 by Fusobacterium nucleatum in oral epithelial cells: multiple signaling pathways and role of commensal bacteria in innate immunity and the epithelial barrier. Infect. Immun. 68, 2907-2915. doi: 10.1128/IAI.68.5.2907-2915.2000

Kumar, D. K. V., Choi, S. H., Washicosky, K. J., Eimer, W. A., Tucker, S., Ghofrani, J., et al. (2016). Amyloid- $\beta$ peptide protects against microbial infection in mouse and worm models of Alzheimer's disease. Sci. Transl. Med. 8:340ra72. doi: 10.1126/scitranslmed.aaf1059

Lai, Y., and Gallo, R. L. (2008). Toll-like receptors in skin infectious and inflammatory diseases. Infect. Disord. Drug Targets 8, 144-155. doi: 10.2174/1871526510808030144

Larrick, J. W., Morgan, J. G., Palings, I., Hirata, M., and Yen, M. H. (1991). Complementary dna sequence of rabbit cap18-a unique lipopolysaccharide binding protein. Biochem. Biophys. Res. Commun. 179, 170-175. doi: 10.1016/0006-291x(91)91350-1

Laube, D. M., Yim, S., Ryan, L. K., Kisich, K. O., and Diamond, G. (2006). Antimicrobial peptides in the airway. Curr. Top. Microbiol. Immunol. 306, 153-182. doi: 10.1007/3-540-29916-56

Lazzaro, B. P., and Clark, A. G. (2003). Molecular population genetics of inducible antibacterial peptide genes in Drosophila melanogaster. Mol. Biol. Evol. 20, 914-923. doi: 10.1093/molbev/msg109

Ledesma, M. D., Martin, M. G., and Dotti, C. G. (2012). Lipid changes in the aged brain: effect on synaptic function and neuronal survival. Progr. Lipid Res. 51, 23-35. doi: 10.1016/j.plipres.2011.11.004

Lee, E. Y., Chan, L. C., Wang, H., Lieng, J., Hung, M., Srinivasan, Y., et al. (2021). PACAP is a pathogen-inducible resident antimicrobial neuropeptide affording rapid and contextual molecular host defense of the brain. Proc. Natl. Acad. Sci. U.S.A. 118:e1917623117. doi: 10.1073/pnas.1917623117

Lee, E. Y., Lee, M. W., and Wong, G. C. L. (2019). Modulation of toll-like receptor signaling by antimicrobial peptides. Seminars Cell Develop. Biol. 88, 173-184. doi: 10.1016/j.semcdb.2018.02.002

Lee, M., Shi, X., Barron, A. E., McGeer, E., and McGeer, P. L. (2015). Human antimicrobial peptide LL-37 induces glial-mediated neuroinflammation. Biochem. Pharmacol. 94, 130-141. doi: 10.1016/j.bcp.2015.02.003

Lee, N. J., and Herzog, H. (2009). NPY regulation of bone remodelling. Neuropeptides 43, 457-463. doi: 10.1016/j.npep.2009.08.006

Lin, Y.-H., Maaroufi, H. O., Ibrahim, E., Kucerova, L., and Zurovec, M. (2019). Expression of human mutant huntingtin protein in drosophila hemocytes impairs immune responses. Front. Immunol. 10:2405. doi: 10.3389/fimmu.2019.02405
Loch, G., Zinke, I., Mori, T., Carrera, P., Schroer, J., Takeyama, H., et al. (2017). Antimicrobial peptides extend lifespan in Drosophila. PLoS ONE 12, e0176689. doi: 10.1371/journal.pone.0176689

López-Otí?n, C., Blasco, M. A., Partridge, L., Serrano, M., and Kroemer, G. (2013). The hallmarks of aging. Cell 153, 1194-1217. doi: 10.1016/j.cell.2013.05.039

Maezawa, I., Zimin, P. I., Wulff, H., and Jin, L.-W. (2011). Amyloid$\beta$ protein oligomer at low nanomolar concentrations activates microglia and induces microglial neurotoxicity. J. Biol. Chem. 286, 3693-3706. doi: 10.1074/jbc.M110.135244

Maffei, F. A., Heine, R. P., Whalen, M. J., Mortimer, L. F., and Carcillo, J. A. (1999). Levels of Antimicrobial Molecules Defensin and Lactoferrin Are Elevated in the Cerebrospinal Fluid of Children With Meningitis. Pediatrics 103, 987-992. doi: $10.1542 /$ peds.103.5.987

Mahlapuu, M., Björn, C., and Ekblom, J. (2020). Antimicrobial peptides as therapeutic agents: Opportunities and challenges. Crit. Rev. Biotechnol. 40, 978-992. doi: 10.1080/07388551.2020.1796576

Mahlapuu, M., Håkansson, J., Ringstad, L., and Björn, C. (2016). Antimicrobial peptides: an emerging category of therapeutic agents. Front. Cell. Infect. Microbiol. 6:194. doi: 10.3389/fcimb.2016.00194

Mangoni, M. L., McDermott, A. M., and Zasloff, M. (2016). Antimicrobial peptides and wound healing: biological and therapeutic considerations. Exp. Dermatol. 25, 167-173. doi: 10.1111/exd.12929

Matsuzaki, K. (2009). Control of cell selectivity of antimicrobial peptides. Biochimica et Biophysica Acta (BBA) - Biomembranes 1788, 1687-1692. doi: 10.1016/j.bbamem.2008.09.013

Maxwell, A. I., Morrison, G. M., and Dorin, J. R. (2003). Rapid sequence divergence in mammalian-defensins by adaptive evolution. Mol. Immunol. 40, 413-421. doi: 10.1016/S0161-5890(03)00160-3

Meade, K. G., Higgs, R., Lloyd, A. T., Giles, S., and O'Farrelly, C. (2009). Differential antimicrobial peptide gene expression patterns during early chicken embryological development. Develop. Comparative Immunol. 33, 516-524. doi: 10.1016/j.dci.2008.10.003

Moir, R. D., Lathe, R., and Tanzi, R. E. (2018). The antimicrobial protection hypothesis of Alzheimer's disease. Alzheimer's Dementia 14, 1602-1614. doi: 10.1016/j.jalz.2018.06.3040

Montero, M., Yon, L., Kikuyama, S., Dufour, S., and Vaudry, H. (2000). Molecular evolution of the growth hormone-releasing hormone/pituitary adenylate cyclase-activating polypeptide gene family. Functional implication in the regulation of growth hormone secretion. J. Mol. Endocrinol. 25, 57-168. doi: $10.1677 /$ jme.0.0250157

Muniz, L., Knosp, C., and Yeretssian, G. (2012). Intestinal antimicrobial peptides during homeostasis, infection, and disease. Front. Immunol. 3, 310. doi: 10.3389/fimmu.2012.00310

Nakayama, K., Okamura, N., Arai, H., Sekizawa, K., and Sasaki, H. (1999). Expression of human $\beta$-defensin-1 in the choroid plexus. Ann. Neurol. 45, 685-685. doi: 10.1002/1531-8249(199905)45:5h685::AID-ANA25i3.0.CO;2-6

Park, S.-C., Moon, J. C., Shin, S. Y., Son, H., Jung, Y. J., Kim, N.-H., et al. (2016). Functional characterization of alpha-synuclein protein with antimicrobial activity. Biochem. Biophys. Res. Commun. 478, 924-928. doi: 10.1016/j.bbrc.2016.08.052

Pazgier, M., Hoover, D. M., Yang, D., Lu, W., and Lubkowski, J. (2006). Human-defensins. Cell. Mol. Life Sci. CMLS 63, 1294-1313. doi: 10.1007/s00018-005-5540-2

Petersen, A. J., Katzenberger, R. J., and Wassarman, D. A. (2013). The innate immune response transcription factor relish is necessary for neurodegeneration in a drosophila model of ataxia-telangiectasia. Genetics 194, 133-142. doi: 10.1534/genetics.113.150854

Petersen, A. J., Rimkus, S. A., and Wassarman, D. A. (2012). ATM kinase inhibition in glial cells activates the innate immune response and causes neurodegeneration in Drosophila. Proc. Natl. Acad. Sci. U.S.A. 109, E656-E664. doi: 10.1073/pnas.1110470109

Postolache, T. T., Akram, F., Lee, E. E., Lowry, C. A., Stiller, J. W., Brenner, L. A., et al. (2020). Increased brain vitamin D receptor expression and decreased expression of cathelicidin antimicrobial peptide in individuals who died by suicide. J. Psychiatric Res. 125, 75-84. doi: 10.1016/j.jpsychires.2020.02.027

Pujol, N., Cypowyj, S., Ziegler, K., Millet, A., Astrain, A., Goncharov, A., et al. (2008). Distinct innate immune responses to infection and wounding in the $C$. elegans epidermis. Curr. Biol. CB 18, 481-489. doi: 10.1016/j.cub.2008.02.079 
Raheem, N., and Straus, S. K. (2019). Mechanisms of action for antimicrobial peptides with antibacterial and antibiofilm functions. Front. Microbiol. 10:2866. doi: 10.3389/fmicb.2019.02866

Rivas-Santiago, B., Hernandez-Pando, R., Carranza, C., Juarez, E., Contreras, J. L., Aguilar-Leon, D., et al. (2008). Expression of cathelicidin LL-37 during mycobacterium tuberculosis infection in human alveolar macrophages, monocytes, neutrophils, and epithelial cells. Infect. Immun. 76, 935-941. doi: 10.1128/IAI.01218-07

Rodrigue, K., Kennedy, K., Devous, M., Rieck, J., Hebrank, A., Diaz-Arrastia, R., et al. (2012). $\quad \beta$-Amyloid burden in healthy aging. Neurology 78, 387-395. doi: $10.1212 /$ WNL.0b013e318245d295

Russo, A. F. (2017). Overview of neuropeptides: awakening the senses? Headache 57, 37-46. doi: 10.1111/head.13084

Scheenstra, M. R., van Harten, R. M., Veldhuizen, E. J. A., Haagsman, H. P., and Coorens, M. (2020). Cathelicidins Modulate TLR-Activation and Inflammation. Front. Immunol. 11, 1137. doi: 10.3389/fimmu.2020.01137

Schröder, N., Schaffrath, A., Welter, J. A., Putzka, T., Griep, A., Ziegler, P., et al. (2020). Inhibition of formyl peptide receptors improves the outcome in a mouse model of Alzheimer disease. J. Neuroinflammation 17, 131. doi: 10.1186/s12974-020-01816-2

Scott, M. G., Gold, M. R., and Hancock, R. E. W. (1999). Interaction of cationic peptides with lipoteichoic acid and gram-positive bacteria. Infect. Immun. 67, 6445-6453. doi: 10.1128/IAI.67.12.6445-6453.1999

Sherwood, N. M., Krueckl, S. L., and McRory, J. E. (2000). The origin and function of the pituitary adenylate cyclase-activating polypeptide (PACAP)/glucagon superfamily. Endocrine Rev. 21, 619-670. doi: 10.1210/edrv.21.6.0414

Shioda, S., Ohtaki, H., Nakamachi, T., Dohi, K., Watanabe, J., Nakajo, S., et al. (2006). Pleiotropic functions of PACAP in the CNS. Ann. New York Acad. Sci. 1070, 550-560. doi: 10.1196/annals. 1317.080

Shireen, T., Venugopal, S., Ghosh, D., Gadepalli, R., Dhawan, B., Mukhopadhyay, K., et al. (2009). In vitro antimicrobial activity of alpha-melanocyte stimulating hormone against major human pathogen staphylococcus aureus. Peptides 30 , 1627-1635. doi: 10.1016/j.peptides.2009.06.020

Sinner, M. P., Masurat, F., Ewbank, J. J., Pujol, N., and Bringmann, H. (2021). Innate immunity promotes sleep through epidermal antimicrobial peptides. Curr. Biol. 31, 564-577. doi: 10.1016/j.cub.2020.10.076

Soltaninejad, H., Zare-Zardini, H., Ordooei, M., Ghelmani, Y., GhadiriAnari, A., Mojahedi, S., et al. (2021). Antimicrobial peptides from amphibian innate immune system as potent antidiabetic agents: a literature review and bioinformatics analysis. J. Diabetes Res. 2021, e2894722. doi: $10.1155 / 2021 / 2894722$

Soscia, S. J., Kirby, J. E., Washicosky, K. J., Tucker, S. M., Ingelsson, M., Hyman, B., et al. (2010). The Alzheimer's disease-associated amyloid $\beta$-protein is an antimicrobial peptide. PLoS ONE 5, e9505. doi: 10.1371/journal.pone.0009505

Souza-Moreira, L., Campos-Salinas, J., Caro, M., and Gonzalez-Rey, E. (2011). Neuropeptides as pleiotropic modulators of the immune response. Neuroendocrinology 94, 89-100. doi: 10.1159/000328636

Sun, Y., and Shang, D. (2015). Inhibitory effects of antimicrobial peptides on lipopolysaccharide-induced inflammation. Mediators Inflammation 2015, e167572. doi: 10.1155/2015/167572

Suzuki, K., Nakamura, K., Shimizu, Y., Yokoi, Y., Ohira, S., Hagiwara, M., et al. (2021). Decrease of $\alpha$-defensin impairs intestinal metabolite homeostasis via dysbiosis in mouse chronic social defeat stress model. Sci. Rep. 11, 9915. doi: 10.1038/s41598-021-89308-y

Swanson, L. C., Rimkus, S. A., Ganetzky, B., and Wassarman, D. A. (2020). Loss of the antimicrobial peptide metchnikowin protects against traumatic brain injury outcomes in drosophila melanogaster. G3 Genes Gen. Genet. 10, 3109-3119. doi: $10.1534 / \mathrm{g} 3.120 .401377$

Thoma-Uszynski, S., Stenger, S., Takeuchi, O., Ochoa, M. T., Engele, M., Sieling, P. A., et al. (2001). Induction of direct antimicrobial activity through mammalian toll-like receptors. Sci. (New York, N.Y.) 291, 1544-1547. doi: $10.1126 /$ science.291.5508.1544

Tiffany, H. L., Lavigne, M. C., Cui, Y.-H., Wang, J.-M., Leto, T. L., Gao, J.-L., et al. (2001). Amyloid-induces chemotaxis and oxidant stress by acting at formylpeptide receptor 2 , a g protein-coupled receptor expressed in phagocytes and brain *. J. Biol. Chem. 276, 23645-23652. doi: 10.1074/jbc.M10103 1200
Tjabringa, G. S., Ninaber, D. K., Drijfhout, J. W., Rabe, K. F., and Hiemstra, P. S. (2006). Human cathelicidin LL-37 is a chemoattractant for eosinophils and neutrophils that acts via formyl-peptide receptors. Int. Arch. Allergy Immunol. 140, 103-112. doi: $10.1159 / 000092305$

Toda, H., Williams, J. A., Gulledge, M., and Sehgal, A. (2019). A sleep-inducing gene, nemuri, links sleep and immune function in Drosophila. Science 363, 509-515. doi: 10.1126/science.aat 1650

Tornesello, A. L., Borrelli, A., Buonaguro, L., Buonaguro, F. M., and Tornesello, M. L. (2020). Antimicrobial peptides as anticancer agents: functional properties and biological activities. Molecules 25, 2850. doi: 10.3390/molecules25122850

Tremblay, S., Côté, N. M. L., Grenier, G., Duclos-Lasnier, G., Fortier, L.-C., Ilangumaran, S., et al. (2017). Ileal antimicrobial peptide expression is dysregulated in old age. Immun. Ageing 14, 19. doi: 10.1186/s12979-017-0101-8

Verjans, E.-T., Zels, S., Luyten, W., Landuyt, B., and Schoofs, L. (2016). Molecular mechanisms of LL-37-induced receptor activation: an overview. Peptides 85, 16-26. doi: 10.1016/j.peptides.2016.09.002

Wang, G. (2014). Human Antimicrobial peptides and proteins. Pharmaceuticals 7, 545-594. doi: 10.3390/ph7050545

Wang, M., Peng, I.-F., Li, S., and Hu, X. (2020). Dysregulation of antimicrobial peptide expression distinguishes Alzheimer's disease from normal aging. Aging 12, 690-706. doi: 10.18632/aging.102650

Wauson, E. M., Dbouk, H. A., Ghosh, A. B., and Cobb, M. H. (2014). G protein-coupled receptors and the regulation of autophagy. Trends Endocrinol. Metabolism 25, 274-282. doi: 10.1016/j.tem.2014.03.006

White, M. R., Kandel, R., Tripathi, S., Condon, D., Qi, L., Taubenberger, J., et al. (2014). Alzheimer's associated $\beta$-amyloid protein inhibits influenza a virus and modulates viral interactions with phagocytes. PLoS ONE 9:e101364. doi: 10.1371/journal.pone.0101364

Wong, E., and Cuervo, A. M. (2010). Autophagy gone awry in neurodegenerative diseases. Nat. Neurosci. 13, 805-811. doi: 10.1038/nn.2575

Xu, X., Cai, X., Zhu, Y., He, W., Wu, Q., Shi, X., Fang, Y., and Pei, Z. (2018). MFG-E8 inhibits $\mathrm{A} \beta$-induced microglial production of cathelicidin-related antimicrobial peptide: A suitable target against Alzheimer's disease. Cell. Immunol. 331, 59-66. doi: 10.1016/j.cellimm.2018.05.008

Yang, D., Chen, Q., Schmidt, A. P., Anderson, G. M., Wang, J. M., Wooters, J., et al. (2000). Ll-37, the neutrophil granule-and epithelial cell-derived cathelicidin, utilizes formyl peptide receptor-like 1 (fprl1) as a receptor to chemoattract human peripheral blood neutrophils, monocytes, and t cells. J. Exp. Med. 192, 1069-1074. doi: 10.1084/jem.192.7.1069

Zehrbach, A. M. D., Rogers, A. R., and Tarr, D. E. K. (2017). An investigation of the potential antifungal properties of CNC-2 in caenorhabditis elegans. J. Nematol. $49,472-476$

Zhang, Q.-Y., Yan, Z.-B., Meng, Y.-M., Hong, X.-Y., Shao, G., Ma, J.-J., et al. (2021). Antimicrobial peptides: mechanism of action, activity and clinical potential. Mil. Med. Res. 8, 48. doi: 10.1186/s40779-021-00343-2

Zugasti, O., and Ewbank, J. J. (2009). Neuroimmune regulation of antimicrobial peptide expression by a noncanonical TGF- signaling pathway in Caenorhabditis elegans epidermis. Nat. Immunol. 10, 249-256. doi: $10.1038 /$ ni. 1700

Conflict of Interest: The authors declare that the research was conducted in the absence of any commercial or financial relationships that could be construed as a potential conflict of interest.

Publisher's Note: All claims expressed in this article are solely those of the authors and do not necessarily represent those of their affiliated organizations, or those of the publisher, the editors and the reviewers. Any product that may be evaluated in this article, or claim that may be made by its manufacturer, is not guaranteed or endorsed by the publisher.

Copyright (C) 2022 Stuart, Franitza and E. This is an open-access article distributed under the terms of the Creative Commons Attribution License (CC BY). The use, distribution or reproduction in other forums is permitted, provided the original author(s) and the copyright owner(s) are credited and that the original publication in this journal is cited, in accordance with accepted academic practice. No use, distribution or reproduction is permitted which does not comply with these terms. 